Revista Aspas

ppgac - USP

Especial

\title{
POETIZANDO CIDADES ENTRE NUVENS, PALAVRAS E CARDUMES
}

\section{POETICIZING CITIES AMONGST CLOUDS, WORDS AND SHOALS}

\section{POETIZANDO CIUDADES ENTRE NUBES, PALABRAS Y CARDÚMENES}

\section{Candice Didonet}

\section{Candice Didonet}

Artista e pesquisadora do corpo. Doutoranda em Estudos Artísticos pela Universidad Francisco José de Caldas na Facultad de Artes - ASAB de Bogotá. Professora adjunta do

Departamento de Artes Cênicas da Universidade Federal da Paraíba. Mestre em Dança com bolsa da Fundação de Amparo à

Pesquisa do Estado da Bahia e especialista em Estudos Contemporâneos em Dança pela Universidade Federal da Bahia. Bacharel em Comunicação das Artes do Corpo pela PUC-SP com bolsa do PIBIC/CEPE e da Fundação São Paulo. 


\section{Resumo}

Este texto apresenta descrições de práticas performativas que mobilizam a percepção das relações entre corpo, natureza e cidade tendo a pesquisa artística como mote. O acionamento de metáforas em acontecimentos poéticos resgata a cidade expandida no corpo e, a arte, como conexão criativa atrelada a processos de sensibilização à realidade.

Palavras-chave: pesquisa artística, poesia urbana, práticas performativas

\section{Abstract}

This text presents descriptions of performative practices that mobilize the perception of the relationships among body, nature and city, with artistic research as a motto. The move of metaphors in poetic happenings rescues a city expanded in the body and, the art, as a creative connection linked to processes of sensitizing the reality

Keywords: artistic research, urban poetry, performatives practices

\section{Resumen}

Este texto presenta descripciones de prácticas performativas que movilizan la percepción de las relaciones entre cuerpo, naturaleza y ciudad teniendo la investigación artística como motivación. El accionamiento de metáforas en cualidad de acontecimientos poéticos rescata la ciudad expandida en el cuerpo y, el arte, como conexión creativa vinculada a procesos de sensibilización a la realidad.

Palabras clave: investigación artística, poesía urbana, prácticas performativas

A escrita que aqui se inicia busca materializar reflexões e serão apresentadas três práticas performativas, em que, metáforas poéticas nutrem sensivelmente outros modos de apreensão da cidade a partir de relações entre corpo e natureza friccionadas no contexto urbano. Entendendo que práticas artísticas ressignificam espaços de circulação de cidades: ruas, bairros, praças e espaços culturais, centros e periferias, quando, atravessadas pelas artes do corpo evocam o sentido crítico do ir e vir no giro urbano e“[...] é importante viver a experiência de nossa própria circulação pelo 
mundo, não como uma metáfora, mas como fricção [...]" (KRENAK, 2019, p. 14).

Pensar as cidades de fora para dentro, que valorizam o tempo e a experiência do espaço com a corporeidade que realoca a pressa do deslocamento. Viver as cidades como cidadãos e não apenas consumidores. As cidades voltadas para os coletivos. As cidades afetivas que se encontram em tempos de conexões entre pessoas gerando encontros reflexivos, aprendizados e trocas.

\begin{abstract}
No contexto hiper-capitalista neo-liberal, a natureza urbana é reduzida em instrumento de mais valia nos processos de urbanização e território, e percebemos a maneira como reservas, parque e outras formas de categorização e regulação de natureza na cidade, estabelecidas como áreas de preservação ou conservação, interagem e potencializam a forma excludente com a qual operam os meios do capital e transformam em mercadoria muitas relações (FONSECA \& BRITTO, 2019, p. 52).
\end{abstract}

Corpo, natureza e cidade. Metáforas que interseccionam relações desta tríade com práticas artísticas que além de figuras de linguagem são pensadas para ativar modos de ações e encontros possíveis. Ao salientar diferentes compreensões de mundo, algumas metáforas ${ }^{1}$ resgatam caminhos cognitivos e imaginários compreendendo a efemeridade da arte, bem como, a poesia de acontecimentos ordinários e próximos da vida cotidiana em contextos urbanos.

Os conceitos que governam nosso pensamento não são meras questões do intelecto. Eles governam também nossa vida cotidiana e até os detalhes mais triviais. Eles estruturam o que percebemos, a maneira como nos comportamos no mundo e o modo como nos relacionamos com outras pessoas. Tal sistema conceptual desempenha, portanto, um papel central na definição de nossa realidade cotidiana. Se estivermos certos, ao sugerir que esse sistema conceptual é em grande parte metafórico, então o modo como pensamos, o que experienciamos e o que fazemos todos os dias são uma questão de metáfora (LAKOFF \& JOHNSON, 2002, p. 45).

\footnotetext{
${ }^{1}$ Com metáforas ampliadas para além de sua compreensão apenas como figuras de linguagem é possível articular conceitualmente a este texto o fenômeno da pareidolia. A pareidolia está relacionada e pode ser considerada uma metáfora "ligada à imagem", ou ainda, uma capacidade cognitiva/sensitiva de ativar imagens em áreas disformes e imaginar desenhos a partir de rastros indefinidos no espaço. Um exemplo de pareidolia é o de enxergar formas nas nuvens.
} 
As metáforas atreladas a nuvens, palavras e cardumes serão descritas poeticamente ao longo deste texto como ativadoras sensíveis e conectivas entre pessoas e cidades. O pressuposto desta escrita é ascender chamas para ações que cutuquem o que há de mais cotidiano e ameaçado pela humanidade: as cidades dentro do planeta, o planeta dentro das cidades, afinal, [...] "Há mundo por vir?" [...] (DANOWSKI \& VIVEIROS DE CASTRO, 2017, p. 13). É fundamental viver as cidades, hoje, com metáforas que questionem modos de existir simultaneamente dentro delas.

Ativar o acionamento de metáforas para suas condições de vivências é ativar histórias e acontecimentos, como sugerido pela pesquisadora Donna Haraway (2000). Como fricção, as metáforas tornam-se fontes inesgotáveis para se chegar, também, a não literalidade do mundo. Haraway oferece provocações que, ampliadas às condições de vida das metáforas - mesmo quando discursivas e biológicas- voltam todas atenções para a simultaneidade entre realidade e ficção, materialidade e semiótica, objeto e tropo.

\section{nuvem particular}

Nuvens em suas existências da vida cotidiana. Gotas de seus pingos são como lágrimas nos olhos. Metáfora para ser gente e poesia, para (sobre)viver em tempos difíceis. Em seus significantes as nuvens sustentam mundos por vir. De cima, nuvens flutuam e olham para a terra invertendo lugar. A gravidade se atira ao céu: nuvem é só uma vez.

\footnotetext{
Da mesma forma um céu sem nuvens. A esse propósito observo que o prazer da variedade e da incerteza prevalece sobre o da aparente infinitude e o da imensa uniformidade. Daí que um céu variadamente esparso de pequenas nuvens será talvez mais agradável de se ver do que um céu completamente limpo; e a vista do céu talvez terá menos encanto que a da terra, do campo, etc. porquanto menos variada (e também menos semelhante a nós, menos íntima, menos ligada às nossas coisas, etc.) [...] (CALVINO, 1990, p. 77).
}

As nuvens remetem paisagens na falha, quase nula e problemática relação entre corpo, natureza e cidade. Se nuvem aparece e desaparece 
como água, sua existência como paisagem indica passagem. Nas cidades, tantas vezes, em pleno deslocamento, correria: olhar pro céu. Nuvens acolhem o corpo em conexão planetária.

\begin{abstract}
Seja recurso, paisagem, cenário ou valor - a natureza é historicamente reconfigurada nos seus sentidos e existências. Hoje estão em pleno curso novas transições da natureza no contexto da cidade contemporânea, e estas transições determinam grande parte da pesquisa urbana [...] (FONSECA \& BRITTO, 2019, p. 52).
\end{abstract}

A importância da observação das nuvens nas cidades é fundamental para abrir leituras sensíveis. Entre corpos e cidades, as ações de observá-las tornam-se um campo de aprendizados para os entendimentos dos contextos urbanos: dos fluxos de deslocamento que se impõe, de outros caminhos, das frestas possíveis para caminhar. Em seus movimentos, as nuvens estão sempre a revelar transformações anunciando tempestades. Nos chãos, as nuvens ressoam sol.

Ainda que a observação de nuvens seja um gatilho poético e metafórico para muitas experiências vividas na cidade, "Um observador de nuvens não é um catalogador - meteorologistas estão ocupados classificando para nós os diferentes gêneros, espécies e variedades de nuvens" (PINNEY, 2008, p. 26). A observação de nuvens como prática cotidiana fundamental para a sobrevivência na cidade compreende as ações de atentar às atividades cognitivas que geram modos de se posicionar corporalmente no espaço urbano.

Da observação de nuvens nasce a primeira pesquisa artística que será descrita neste texto: nuvem particular². Desde o princípio, os sentidos metafóricos se mostraram como ampliadores de percepção para as práticas performativas testadas. Para chegar na pesquisa de movimento foi preciso estudar materialidades, catalogar visibilidades possíveis e perceber volumes

\footnotetext{
${ }^{2}$ nuvem particular (2008) foi também nome artístico para o trabalho de conclusão de curso em Comunicação da Artes do Corpo (PUC-SP) intitulado: Escrever, dizer, dançar? A monografia teve orientação da Profa. Dra. Christine Greiner, professora do Departamento de Artes da PUC-SP onde coordena o Centro de Estudos Orientais. Para acessar seu currículo lattes ver página disponível em: http://buscatextual.cnpq.br/buscatextual/visualizacv.do?id=K4799930T1
} 
poéticos entre (des)aparecimentos instaurados no cerne de existência das nuvens.

nuvem nasce como um "vestível em fluxo" (DINIZ, 2012). O entendimento do vestível em fluxo considera a relação entre a pesquisa em dança com os demais componentes coimplicados na prática do movimento. Problematizando a relação do que se veste em cena coimplicado ao corpo e ao movimento que constituem a própria dança, os vestíveis em fluxo apontam a intersecção entre corpos e objetos ampliando a percepção entre pesquisa artística em dança, cena performativa e elementos que a compõe.

Como vestível, o primeiro objeto a constituir a confecção da nuvem foram sacolas plásticas transparentes. Após testar alguns enchimentos com água, fumaça e ar, finalmente, preenchidas de ar, as sacolas foram amarradas entre si com linha de costura que formou uma volumosa e delicada saia. Aproximadamente setenta sacolas transparentes preenchidas de ar, juntas, formariam uma imagem próxima de nuvem, próxima de balão.

Depois da primeira tempestade e muitas sacolas perdidas, a ideia era criar uma estrutura autossustentável que pudesse ser montada/desmontada reaproveitando uma moldagem completamente aderida ao corpo. Em uma estrutura de elásticos confeccionada como um vestido, as sacolas foram primeiramente preenchidas de ar e amarradas especialmente para serem desamarradas. Dois nós: primeiro no preenchimento de ar delas mesmas, depois na estrutura de elásticos aderida ao corpo. Uma nova maneira de preencher $\mathrm{o}$ ar das sacolas aparecia além do sopro, o ar do ambiente, uma coreografia entre sopro e captura de ar do espaço. Depois de preenchidas de ar, as sacolas individualmente iam sendo amarradas na estrutura de elásticos e se expandindo até formar um corpo nuvem pois "[...] do Objeto ao Acontecimento: nós somos o molde a vocês cabe o sopro" (CLARCK, 2006).

As materialidades foram gatilhos de percepção para a pesquisa de movimento: lentidão, deslocamento em fluxo, flutuação, apoio do peso no ar, caminhada incerta que produz sonoridade com a friç̧ão na sacola ${ }^{3}$. Despir a

\footnotetext{
${ }^{3}$ Para assistir trechos de nuvem particular ver: https://www.youtube.com/watch?v=Fm91 H1ukmZ8
} 
nuvem do corpo apontou ainda a sua montagem não somente como vestível, mas como objeto, ampliando continuamente e indeterminadamente os tempos e espaços não intencionais da caminhada artística.

\begin{abstract}
Com efeito, pôr em crise as poucas certezas mal alcançadas permite que se abra a mente a mundos e a possibilidades antes inexplorados, convida a reinventar tudo: a ideia que se tem da cidade, a definição que se tem de arte e de arquitetura, o lugar que se ocupa neste mundo. Ocorre a libertação de convicções postiças e começa-se a recordar que o espaço é uma fantástica invenção com o qual se pode brincar, como as crianças. Um mote que guia nossas caminhadas é "quem perde tempo ganha espaço". Se de fato, se quer ganhar outros espaços é preciso saber brincar, sair deliberadamente de um sistema funcional-produtivo e entrar num sistema não funcional e improdutivo. É preciso aprender a perder tempo, a não buscar o caminho mais curto, a deixar-se conduzir pelos eventos, a dirigir-se a estradas impraticáveis onde seja possível "topar" talvez encalhar-se para falar com as pessoas que se encontram ou saber deter-se, esquecendo o que se deve agir. Saber chegar ao caminhar não intencional, ao caminhar indeterminado (CARERI, 2013, p. 171).
\end{abstract}

Em sua última aparição pública, nuvem com algumas sacolas a mais foi pendurada como móbile em uma estrutura feita com cano fino de PVC e elásticos. Nesta montagem nuvem sai do corpo compreendendo sua existência como objeto emprestando a classificação de "objeto coreográfico"4. Em um casarão antigo com janelas apontadas para a rua em um canto de parede pintada em azul que incluía uma porta, nuvem ficou pendurada em uma estrutura de varal para que pudesse ser regulada na interação com o público: cabeça de nuvem, céu de nuvem, saia de nuvem, chão de nuvem. Escapou pela porta da frente, expandiu para chover na cidade.

${ }^{4} \mathrm{O}$ termo objeto coreográfico (choreographic objects) foi cunhado pelo coreógrafo estadunidense William Forsythe que realizou a grande exposição "Objetos Coreográficos" com instalações no SESC Pompéia em São Paulo no ano de 2019. A última aparição de nuvem particular, como objeto coreográfico foi no XV SAMAP - Salão Municipal de Artes Plásticas da cidade de João Pessoa - Paraíba, em 2014. 
Figura 1: nuvem particular sendo performada entre os anos de 2008 e 2014 nas cidades de São Paulo, Curitiba e João Pessoa.

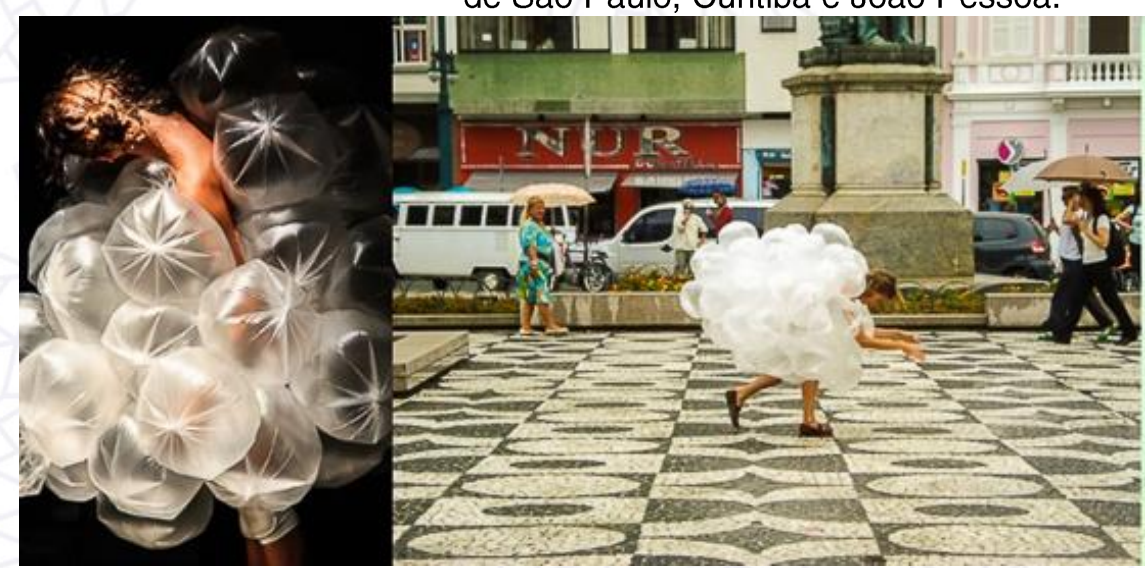

Créditos: Acervo pessoal.

\section{Estudo da materialidade das palavras}

Experienciar cidades e vivê-las corporalmente. Fruições condicionadas aos chãos que as compõe. Como sina transeunte, escrever no chão com objetos coletados de dentro de casa e pedaços da natureza encontrados pelos caminhos: linhas de costura, folhas, pedras, caules, sementes, flores caídas de árvores. Nas intensas idas, vindas e, trocas de cidades, palavras confortam os períodos sem endereço. Palavras lavram a condição de estar situada (por um instante), enquanto durar o click da foto ou o vento não desmanchar nome. Escrever como espaçamento, ler como aterramento. Arquitetar palavras/rotas quase invisíveis nas cidades que engolem e só. Só sol, vento ou so(m)bra e as palavras se desmancham vibrando impermanências. Cavar o lugar da pausa na cidade como tarefa artística. O fluxo em volta faz da palavra jogo de mover e distanciar. Palavras como sínteses de sensações. Na materialidade da captura de suas escritas, no chão, o aqui, o além, lá: a incompletude de nomes. 
Figura 2: NOME LÁ CHÃO. Fotografias feitas entre 2009 e 2020 nas cidades de João Pessoa, Salvador e São Paulo.

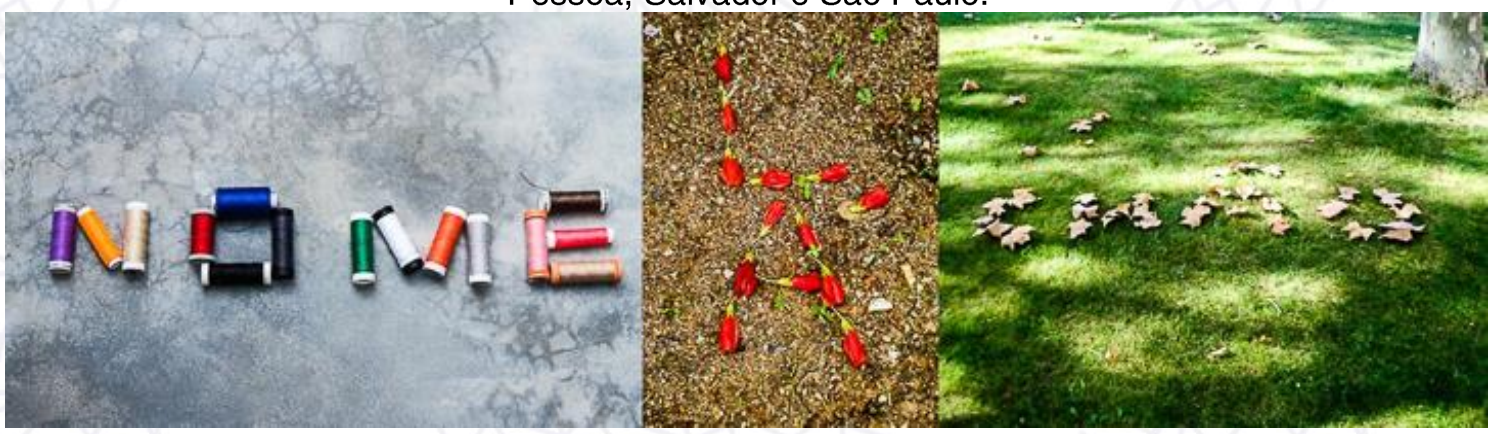

Créditos: Acervo pessoal.

Estudo da Materialidade das Palavras foi desenvolvido no programa de Novos Coreógrafos - Novas Criações: Site Specific (NC-NC:SS) do Centro Cultural São Paulo - CCSP juntamente com pesquisa de mestrado na Escola de Dança da Universidade Federal da Bahia. ${ }^{5}$ A pesquisa consistia em caminhos sugeridos para leituras e visualizações da ação coreográfica de "escrever" e se deu na composição de palavras com materiais coletados em percursos de caminhadas e deslocamentos entre lugares externos e internos da praça das bibliotecas do Centro Cultural São Paulo. A abordagem site specific sugere uma metodologia que leva em consideração a relação entre dança e lugar. Porém ao carregar o problema da tradução, as duas palavras juntas permanecem sendo testadas em sua leitura. E se site specific pode ser entendido como metodologia de trabalho quais os imbricamentos entre pesquisa artística em dança que podem ser revelados em diferentes traduções?

\footnotetext{
${ }^{5}$ A dissertação de mestrado intitulada "Escritas do corpo: palavras ações" (2012) foi orientada pela Profa. Dra. Jussara Setenta, professora da Escola de Dança da Universidade Federal da Bahia e autora do livro "O fazer-dizer do corpo: dança e performatividade" (EDUFBA, 2008). Para acessar seu currículo lattes ver página disponível em:

http://buscatextual.cnpq.br/buscatextual/visualizacv.do?id=K4774848D3

Estudo da materialidade das palavras (2010) também foi performada no VI Seminário de Pesquisa em Artes da Faculdade de Artes do Paraná (2011); no Projeto Danças Performativas do Museu Oscar Niemeyer, Curitiba (2012); no projeto Crítica com a Dança do artista-pesquisador Joubert Arrais, em Fortaleza (2013) e no Seminário Articulações Mundos Possíveis, realizado no Museu da cidade do Recife (2014).
} 
Uma tradução literal para o termo em inglês site specific seria lugar específico. Um lugar é quase um pleonasmo. Qual o lugar de "lugar" na linguagem? Como esta palavra se confronta com outras, suas vizinhas por sinonímia? E como ela ocupa territórios semelhantes, mas que se diferenciam, se contrapõem e se especializam como vocábulos para se tornarem necessários? As palavras podem ser lugares e os lugares também podem ser palavras. Frases. Textos. Camadas, peles históricas e sociais, simbólicas e políticas. Arquitetônicas... Arenas, palcos, molduras e paredes, tela e papel. Marcos institucionais. A divisão entre a cena e a plateia, a coxia quase sempre escondida... De um lado o artista, do outro o público. Todas essas divisões e segregações de espaços e pessoas engendram arquiteturas e funções rigidamente determinadas e compartilham uma ideologia. Uma visão de mundo onde as práticas artísticas são dissociadas do cotidiano e passaram a fazer parte do domínio técnico, específico, especializado, e de uma hegemonia de discurso (eurocentrado, falocentrado, moderno, etc...). A construção de uma "História Universal". Mas como reestabelecer a ideia de que se tratam de formas transitórias e de estados provisórios? Como explicitar que tais estruturas, funcionamentos e sistemas exigem sua aniquilação vindoura? Existe uma dialética intrínseca à ideia e à prática de arte. Algo que pede a sua superação, sua diluição no corpo dos indivíduos e nos corpos sociais, tornando-a tão necessária e, por isso mesmo, tão corriqueira quanto 0 ato de respirar. Mais do que um lugar específico vamos pensar em situações, em tempos e espaços determinados, inscritos no mundo e na carne. Vamos pensar que nosso trabalho hoje é fazer com que sejamos, um dia, desnecessários" (PACKER, 2010, p. 24).

A palavra olho, por exemplo. Escrita com pequenas folhas amarelas arredondadas. Na junção de seu arranjo, as mãos em gestos circulares encontraram a letra "O", o "L" e o "H" meio desajeitados em letra maiúscula compondo uma imagem tácita ${ }^{6}$. Então como se organizam os movimentos do corpo em relação à escrita com palavras? Podem as palavras serem consideradas ações do corpo? Compor palavras a partir de materialidades e objetos altera o modo de produção e recepção de suas leituras e espacialidades?

Quando o poeta evoca o mineral como tudo que está em estado de
palavra, da palavra escrita, penso, sobretudo nessa materialidade
da escrita que guia a artista de dança em sua pesquisa, mas que
tange também ao papel, à tela, ao chão e, também, à carne dessas
palavras, essas coisas feitas de palavras. Dá uma ideia de
permanência, de uma experiência tátil, embora estejamos falando

${ }^{6}$ Para assistir trechos da performance em que palavras foram escritas com materiais coletados pelos arredores do Centro Cultural São Paulo e jornais residuais de dentro, ver:

https://www.youtube.com/watch?v=8julk Exd-A. 
de uma escrita efêmera, além das noções de superfície, de concretude, de relevo e de textura (CASTRO, 2015, p. 86).

Palavras escritas no chão sofrem a ação do lugar. Palavra chutada, palavra desmontada, palavra pisada. No pleonasmo do chão, gestos e materiais agregam carnadura à escrita, o que permite às palavras serem percebidas em seus estados situacionais. Sempre em estudo, as palavras reverberam lugares na criação artística. A coreografia como procedimento de pesquisa dialoga em campo expandido com a performatividade presente ao ato de escrever. Interessa pensar nos movimentos da escrita que diferentes gestos desenham no espaço registrando coreografias em acontecimento.

No registro de uma de suas experimentações, por exemplo, a palavra TEMPO, escrita com pequenas e delicadas flores vermelhas, é fragilmente desfeita pelo vento, justamente pela exposição ao tempo que faz efêmera essa escrita. As palavras tornam-se encarnadas, ganham corpo, mas, no entanto, estão invariavelmente condenadas ao rápido desaparecimento pela ação do tempo, o que evidencia o próprio movimento da escrita (CASTRO, 2015, p. 86).

Figura 3: TEMPO (2009), Salvador.

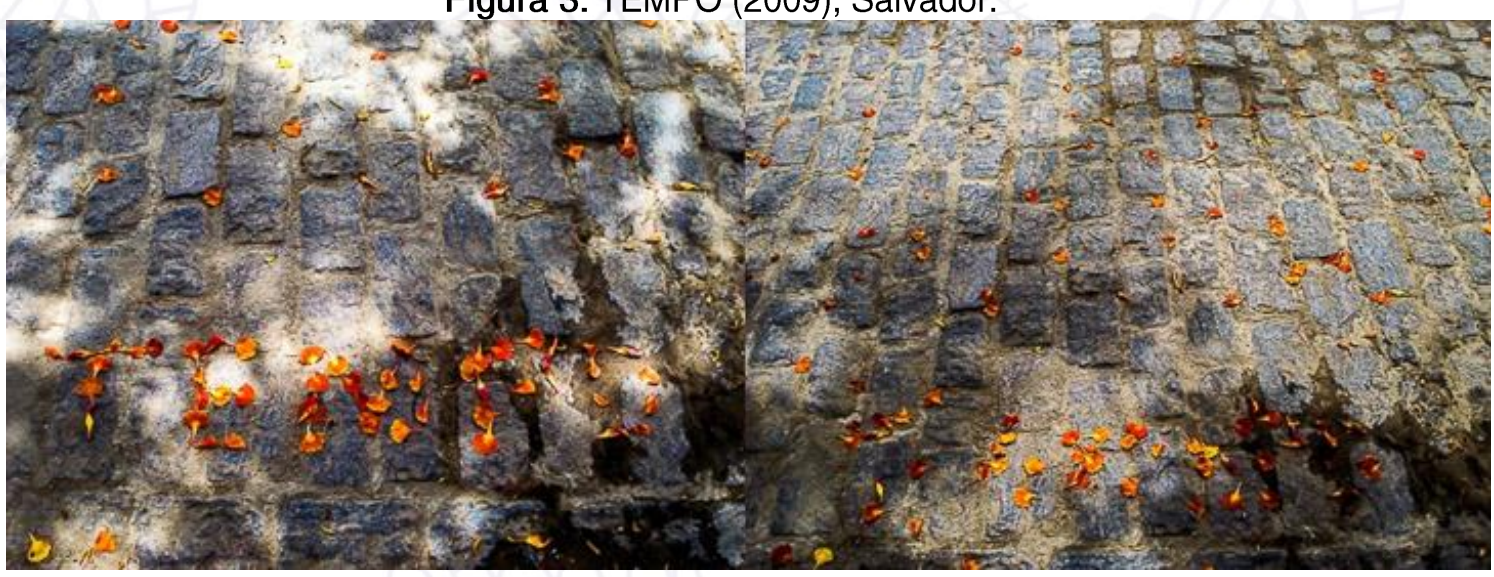

Créditos: Acervo pessoal.

\section{Cardume}

Trocar palavras por gestos, deixar pensamentos como iscas. Marcar o lugar de encontro. Escola, rua, universidade, teatro. Entrar e sair das bordas da cidade. Ativação tácita entre fronteiras, cardumes de pessoas. Apalpar o corpo líquido desenhando contornos fluidos que escoam no espaço. Corpos reunidos. Depois de aguçada a fronteira individual em círculo, é tempo de 
trabalhar o cardume em par. Este é o momento de transferir a ativação da borda individual para o contorno do outro até a ampliação desta sensação para o espaço. Uma grande borda se desenha e se desloca para o corpo coletivo ${ }^{7}$ : um cardume vai se formando com ativação sensória de corpo expandido no contorno do corpo conjunto. A última etapa é o deslocamento. Com o desafio de como deslocar-se junto, o corpo coletivo vai movendo na trajetória que caminhos aprontam ao cardume. Alguns elementos dinâmicos como a pausa e o escape são sugeridos para a percepção temporal da coreografia que vai se desenhando. $O$ entorno imaginado como água é proposição de trajetória em fluxo. Incerta como a vida a trajetória acontece variando de tempo.

A água é imaginada como um elemento de atenção corporal na proposição dos cardumes de pessoas. Embora a materialidade da água não seja tangível, é proposital pensar um cardume de pessoas com pés flutuantes que colocam em atenção a dura e fria condição do bípede: aquele que vai pisoteando o mundo andando para frente, na cidade, preocupado em se deslocar ignorando tudo em sua volta. A água imaginada para a condição do deslocamento busca tecer chãos móveis. Assim como os peixes de um cardume, água resgata uma conexão com a natureza corporal. Segundo Fortes (2006) a água pode ser trazida em conotações simbólicas que materializam sensações na pesquisa artística, aqui neste caso específico, como material sensório e foco de atenção espacial imaginada como contexto de ação performativa.

\footnotetext{
${ }^{7}$ Cardume (2014) nasce da experiência docente pensando na relação entre aula e performance a partir da pergunta sugerida por Butler (2018): quais as possíveis formas corpóreas de reunião e como podem ser vivenciadas? Para trazer exemplos dos lugares de compartilhamento dos cardumes em águas imaginadas citam-se inúmeras aulas dos cursos de Dança e Teatro da Universidade Federal da Paraíba, aulas ministradas ao curso de especialização em Dança da Universidade Federal do Rio Grande do Norte (2017); Mostra Sala Aberta do curso de bacharelado em Dança da Universidade Federal Uberlândia (2017); SPA - Seminário de Pesquisas em Andamento do Programa de Pós-Graduação em Artes Cênicas da Universidade de São Paulo (2017); COLIPETE - Colóquio Internacional de Pedagogia do Teatro realizado na Universidade Federal do Maranhão (2018) e o Encontro Nacional dos Pesquisadores em Dança realizado na Escola de Dança da Universidade Federal da Bahia (2019).

${ }^{8} \mathrm{Na}$ discussão do comitê temático "Corpo e Política: implicações em modos de aglutinação em dança" coordenado pela Profa. Dra. Helena Bastos (USP) junto ao ANDA - Associação Nacional dos Pesquisadores em Dança, os artistas e professores da Escola de Dança da UFBA Edu O. e Natália Rocha sugeriram a leitura do texto acerca da dura e fria condição bípede: https://www.correio24horas.com.br/noticia/nid/voces-bipedes-me-cansam/
} 
Figura 4: Cardume entre 2017 e 2019 nas cidades de São Luís, São Paulo e Uberlândia.

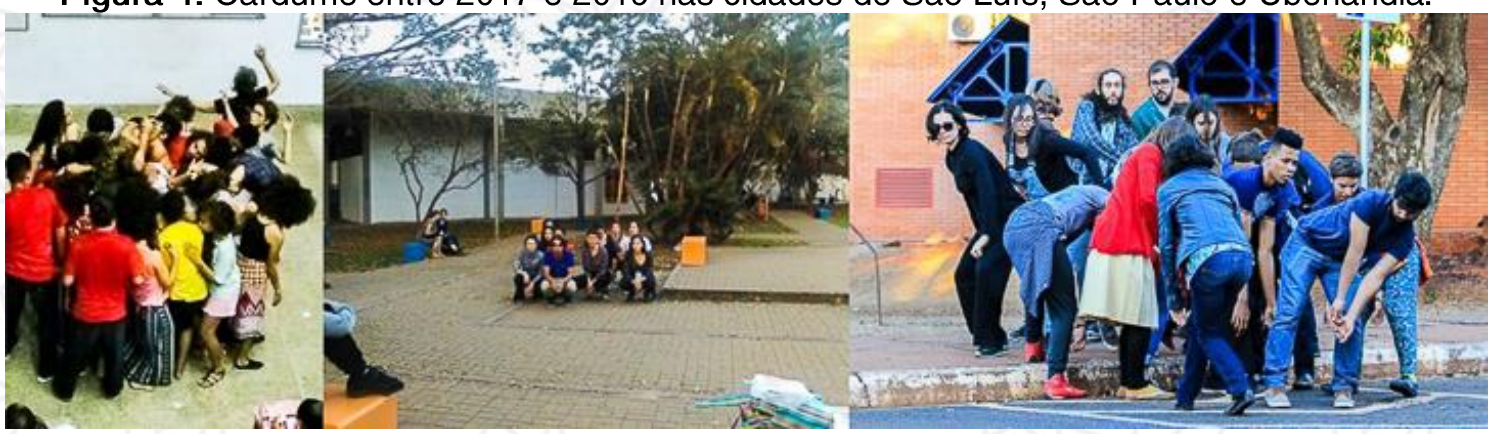

Créditos: Acervo pessoal.

Fiando

Práticas artísticas feitas com a cidade podem resgatar as sensibilizações dentre as experiências de urbano conectando diferentes esferas de compreensão da natureza, fiando, cidades possíveis. Já que o pressuposto da habitação humana, nocivo e prejudicial, consome o planeta, só se escapa da relação de mercadoria estabelecida entre corpos e cidades a partir de sensibilização das relações existentes com a natureza.

Se existe uma ânsia por consumir a natureza, existe também uma por consumir subjetividades - as nossas subjetividades. Então vamos vivê-las com a liberdade que formos capazes de inventar, não botar ela no mercado. Já que a natureza está sendo assaltada de uma maneira tão indefensável, vamos, pelo menos, ser capazes de manter nossas subjetividades, nossas visões, nossas poéticas sobre a existência.[...] $O$ fato de podermos compartilhar esse espaço, de estarmos juntos viajando não significa que somos iguais significa exatamente que somos capazes de atrair uns aos outros pelas nossas diferenças, que deveriam guiar o nosso roteiro de vida. Ter diversidade, não isso de uma humanidade com o mesmo protocolo. Porque isso até agora foi só uma maneira de homogeneizar e tirar nossa alegria de estar vivos (KRENAK, 2019, p. 17).

Poetizar cidades entre nuvens, palavras e cardumes aproxima modos de viver contextos urbanos de dentro para fora. Evocando o miúdo, o desaparecimento e o efêmero são tentativas de manutenção sensível em práticas artísticas que possam resistir aos embates e dificuldades do cotidiano. As fricções e a diversidade de trocas nos campos de conhecimentos 
artísticos empurram o existir a continuar tecendo cidades como mundos possíveis, ainda que, fiando recomeços.

\section{Referências bibliográficas}

ARAUJO, Laura Castro de. A ação da escrita e a escrita em ação: experiências de performance em literatura. Tese (Doutorado em Artes Cênicas). Universidade Federal da Bahia, Salvador: 2015. Disponível em: https://repositorio.ufba.br/ri/handle/ri/17373?mode=full . Acesso em 12 de julho de 2017.

BASTOS, Helena (org). Corpo e Cidade: moveres entre aproximações e distanciamentos. São Paulo: Cooperativa Paulista de Dança, 2015.

BUTLER, Judith. Corpos em aliança e a política das ruas: notas para uma teoria performativa de assembleia. Rio de Janeiro: Editora Civilização Brasileira, 2018.

CALVINO, Italo. Seis propostas para o próximo milênio. São Paulo: Companhia das Letras, 1990.

CARERI, Francesco. Walkscapes: o caminhar como prática estética. São Paulo: Editora G. Gilli, 2013.

CENTRO CULTURAL SÃO PAULO. Catálogo da Mostra Novos Coreógrafos: Novas Criações - Site Specific. São Paulo: CCSP, 2010. 24 p.

DANOWSKI, Deborah. VIVEIROS DE CASTRO, Eduardo. Há mundo por vir? Ensaio sobre os medos e os fins. Florianópolis: Instituto Socioambiental, 2017.

DIDONET, Candice. Escritas do corpo: palavras ações. Dissertação (Mestrado em Dança). Universidade Federal da Bahia, Salvador: 2012. Disponível em https://repositorio.ufba.br/r//bitstream/ri/10083/1/Candice\%20Didonet.pdf .Acesso em 02 de dezembro de 2012.

DINIZ, Carolina de Paula. Vestíveis em fluxo: a relação implicada entre corpo, movimento e o que se veste na cena contemporânea da dança. Dissertação (Mestrado em Dança). Universidade Federal da Bahia, Salvador: 2012. Disponível em: https://repositorio.ufba.br/ri/handle/ri/7890 . Acesso em 15 de outubro de 2019. FONSECA, Carolina. BRITTO, Pedro. Entrópicos. Goiânia: Editora Trilhas Urbanas, 2019.

FORTES, Hugo. Poéticas líquidas: a água na arte contemporânea. Tese (Doutorado em Artes Plásticas). Universidade de São Paulo, São Paulo: 2006. Disponível em: 
http://www.teses.usp.br/teses/disponiveis/27/27131/tde-13082009-155421/pt-br.php . Acesso em: 25 de janeiro de 2019.

HARAWAY, Donna J. How like a leaf: an interview with Thyrza Nichols Goodeve. New York: Routledge, 2000.

KRENAK, Ailton. Ideias para adiar o fim do mundo. São Paulo: Companhia das Letras, 2019.

LAKOFF, George. JOHNSON, Mark. Metáforas da vida cotidiana. São Paulo: Mercado das Letras, Educ, 2008.

LYGIA Clark, do Objeto ao Acontecimento: nós somos o molde, a vocês cabe o sopro (2006: São Paulo, SP). In: ENCICLOPÉDIA Itaú Cultural de Arte e Culturas Brasileiras. São Paulo: Itaú Cultural, 2020. Disponível em: http://enciclopedia.itaucultural.org.br/evento436847/lygia-clark-do-objeto-ao-acontecimentonos-somos-o-molde-a-voces-cabe-o-sopro-2006-sao-paulo-sp. Acesso em 20 de junho de 2020.

PRETOR-PINNEY, Gavin. [Tradução Cláudio Figueiredo]. Guia do Observador de Nuvens. Rio de Janeiro: Intrínseca, 2008. 